\title{
PELATIHAN DAN PENDAMPINGAN DALAM PEMASARAN PRODUK SIRUP MARKISA MELALUI INTERNET MARKETING
}

\author{
Khoirul Ngibad $^{1)}$, Nambi Sembilu' ${ }^{2}$, Khotmil Ula ${ }^{3)}$ \\ Universitas Maarif Hasyim Latif ${ }^{1)}$ \\ Universitas Maarif Hasyim Latif ${ }^{2)}$ \\ Universitas Maarif Hasyim Latif ${ }^{3)}$ \\ khoirulngibad@dosen.umaha.ac.id
}

\begin{abstract}
ABSTRAK
Di era revolusi industri 4.0 ini, penerapan internet marketing untuk meningkatkan penjualan harus dilakukan oleh para pelaku UMKM (Usaha Mikro Kecil Menengah). Pemasaran secara internet dapat dilakukan menggunakan perangkat elektronik/internet dan media pemasaran online, seperti: website/blog, media sosial (instagram, whatsapp, telegram, line, twitter, dan facebook) dan youtube. Di Desa Jatikalang terdapat UMKM yang bergerak dalam pembuatan sirup markisa. Dalam program PKM (Program Kemitraan Masyarakat), yang kami pilih adalah 1 mitra usaha yang bergerak dalam pembuatan sirup markisa. Berdasarkan hasil observasi, mitra ini belum mengetahui cara pemasaran menggunakan internet marketing untuk pemasaran produk secara online ke seluruh wilayah di Indonesia. Oleh karena itu, tim pengabdian masyarakat akan memberikan pelatihan dalam pemasaran produk sirup markisa melalui internet marketing, yang meliputi: website, fanspage, youtube dan instagram. Kegiatan pelatihan ini dilaksanakan selama dua hari menggunakan beberapa metode, meliputi: penyampaian informasi tentang pentingnya penerapan internet marketing dalam aspek pemasaran dan pelatihan penggunaan website, fanspage, instagram dan youtube untuk pemasaran produk sirup markisa secara online. Pelatihan internet marketing dengan mitra UMKM yang bergerak dalam pembuatan sirup markisa dapat diselenggarakan dengan lancar dan dapat memberikan pengetahuan dan keterampilan kepada mitra dalam penerapan internet marketing (pemasaran secara internet) untuk meningkatkan omset dan income.
\end{abstract}

Kata kunci: internet marketing, sirup markisa, UMKM

\begin{abstract}
In the era of the industrial revolution 4.0, the application of internet marketing to increase sales must be done by the perpetrators of SMEs (Micro, Small and Medium Enterprises). Internet marketing can be done using electronic devices/internet and online marketing media, such as: website/blog, social media (Instagram, WhatsApp, Telegram, Line, Twitter, and Facebook) and YouTube. In Jatikalang village, there is SME engaged in manufacturing of markisa syrup. In the Community Partnership Program, we chose one business partner engaged in the manufacturing of markisa syrup. Based on observations, this partner did not know yet how to use internet marketing for marketing products via online to all regions in Indonesia. Therefore, the community service team will provide training in marketing of markisa syrup products through internet marketing, which includes: website, fanspage, youtube and instagram. This training activity was carried out for two days using several methods, including: delivering information about the importance of applying internet marketing in marketing aspects and training on the use of websites, fanspage, instagram and youtube for marketing of markisa syrup products via online. Internet marketing training with SME partners engaged in manufacturing of markisa syrup can be carried out smoothly and can provide knowledge and skills to partners in the application of internet marketing to increase omset and income company.
\end{abstract}

Kata kunci: internet marketing, markisa syrup, SMEs 


\section{PENDAHULUAN}

\subsection{Analisis Situasi}

Buah markisa merupakan salah satu buah yang dapat digunakan untuk membuat minuman kesehatan, seperti sirup markisa. Sirup merupakan cairan yang kental yang jika akan dikonsumsi harus diencerkan terlebih dahulu untuk mendapatkan kenikmatan rasa. Produsen sirup markisa telah tersebar dari Sabang sampai Merauke. Pembuatan sirup markisa menjadi salah satu jenis usaha menjanjikan yang dapat dilakukan dalam skala kecil. Salah satu daerah di Indonesia yang masyaraktnya mengembangkan usaha pembuatan sirup markisa adalah Desa Jatikalang Kecamatan Krian Kabupaten Sidoarjo. Di Desa Jatikalang terdapat UMKM yang bergerak dalam pembuatan sirup markisa. Dalam program PKM (Program Kemitraan Masyarakat), kami memilih 1 mitra usaha yang bergerak dalam pembuatan sirup markisa dengan profil sebagai berikut:

- Nama Pemilik Usaha : Ibu Wiwik

- Alamat : Jalan RT.04

RW.02 Dusun Jatirejo Desa

Jatikalang Kecamatan Krian Kabupaten Sidoarjo

- Usia : 50 Tahun

- Lama Usaha : 1 Tahun sejak tahun 2018

- Pemasaran : Ketika ada pesanan dari warga desa

- Jenis Bidang Usaha : Pembuatan sirup markisa.

- Jumlah Karyawan : 4 orang (Ibu Nurwihana, Ibu Sutatik, Ibu Nunuk Fauziyah, Ibu Wahyuni)

Volume penjualan produk sirup markisa per hari tidak bisa dipastikan karena Ibu Wiwik hanya membuat sirup untuk dijual ketika ada acaraacara di lingkungan desa atau ketika ada bazar atau ketika ada pesanan dari warga desa. Hal tersebut menyebabkan omset atau income usaha menjadi tidak pasti sehingga perlu adanya strategi untuk meningkatkan omset atau income mitra. Media pemasaran online menggunakan website, fanspage, instagram dan youtube sangat diperlukan agar produk sirup markisa dapat dibeli oleh konsumen dari seluruh wilayah Indonesia. Website, fanspage, instagram dan youtube dari produk markisa dibuat sebaik dan seelegan mungkin agar dapat meningkatkan kepercayaan calon konsumen yang mengakses media pemasaran online tersebut. Langkah selanjutnya, perlu dilakukan optimasi SEO (Search Engine Optimation) dari website tersebut agar dapat berada di halaman 1 google untuk keyword atau kata kunci yang ditembak. Di sisi lain, untuk fanspage, instagram dan youtube perlu dilakukan penambahan follower dan subscriber. Dengan demikian, dapat meningkatkan jumlah calon konsumen yang mengunjungi media pemasaran online tersebut yang berpotensi untuk membeli produk sirup markisa.

Internet marketing (pemasaran online) dapat dijadikan salah satu strategi yang penting dalam rangka untuk memasarkan produk UMKM menggunakan teknologi internet. Beberapa media online yang dapat digunakan untuk memasarkan produk adalah website, fanspage, youtube, Instagram, telegram, whats app dan lain-lain. Banyak penelitian yang menunjukkan efektivitas internet marketing dalam aspek pemasaran, misalnya penjualan dari Billionaire Store lebih efektif menggunakan media online dengan ribuan reseller yang tersebar di seluruh Indonesia. Dengan strategi tersebut, sumber keuntungan CV Billionaire Sinergi Korpora 
mencapai $80 \%$ dari penjualan online (Zulfikar \& Supriyoso, 2019). Hasil penelitian lain juga menunjukkan bahwa promosi produk UMKM makanan dan minuman di kota Pekanbaru menggunakan media online Instagram sangat efektif yang mampu menimbulkan perhatian (attention), ketertarikan (Interest), dan feedback (desire) (Khairani, dkk., 2018). Media Instagram juga merupakan salah satu media online yang efektif untuk digunakan sebagai media promosi penjualan kamar batiqa hotel pekanbaru (Ulfa \& Musadad, 2018). Selain itu, penggunaan marketplace juga efektif dalam membantu usaha kecil dalam memasarkan dan menjual produknya secara online di enam kabupaten di Jawa Timur (Artaya \& Purworusmiardi, 2019).

Efektivitas penggunaan internet marketing dalam aspek pemasaran mendorong para para akademisi dari Perguruan Tinggi untuk melaksanakan pengabdian kepada masyarakat. Pelatihan website dan social media mampu meningkatkan kualitas karyawan dalam penguasaan teknologi dan wawasan pemasaran sehingat mampu meningkatkan jumlah wisatawan yang ingin berkunjung ke Museum di Museum Kraton Kasunanan Surakarta dan tempat wisata lainnya di Surakarta (Triono \& Sari, 2017). Pengabdian kepada masyarakat dengan kegiatan pendampingan tentang literasi marketing (media online) komunitas dengan mitra women entrepreneur melalui online di Jawa Barat dapat meningkatkan pemasaran produk hasil UMKM (Ratnadewi, dkk., 2019). Selain itu, penggunaan digital marketing e-commerce mampu meningkatkan pemesanan produk Dany Collection meningkat sebesar
10\% (Triandini, dkk., 2019). Beberapa mitra yang terlibat dalam pengabdian kepada masyarakat dengan topik pelatihan digital marketing/internet marketing adalah Kelompok Usaha Makanan Ringan di Kota Tarakan meliputi Usaha Mikro Bude Ramdan Usaha Mikro Ar-Raihan (Harto, dkk., 2019), Kelompok PKK Desa Sutojayan (Ermayda, dkk., 2019) dan Kelompok Batik Sojiwan (Yudaninggar, 2019).

\subsection{Permasalahan Mitra}

Permasalahan mitra dalam aspek pemasaran adalah kurangnya pengetahuan dalam bidang pemasaran produk yang berpengaruh besar dalam peningkatan omset atau income usaha mitra. Mitra kurang mengetahui cara pemasaran menggunakan internet marketing agar produk mitra dapat dipasarkan secara online ke seluruh wilayah di Indonesia.

\section{METODE PELAKSANAAN}

Metode pelaksanaan kegiatan pengabdian meliputi:

1. Analisis situasi, yaitu tim pengabdian masyarakat mendatangi lokasi mitra PKM untuk melakukan wawancara yang bertujuan untuk mengetahui profil mitra dan mendata permasalahan yang sedang dihadapi mitra yang meliputi aspek produksi, manajemen dan pemasaran. Output dari tahapan ini adalah adanya kesepakatan bersama terhadap solusi yang ditawarkan.

2. Pengembangan media pemasaran online yang dilakukan oleh tim pengusul. Kegiatan yang dilakukan oleh tim pengusul yaitu mengumpulkan data mitra berupa profil yang digunakan sebagai 
konten materi di website, fanspage, youtube dan Instagram.

3. Pelatihan yang diawali dengan penyampaian informasi tentang pentingnya penerapan internet marketing dalam aspek pemasaran. Media onlie yang biasa digunakan untuk penjualan produk antara lain: website, fanspage, instagram dan youtube. Pada pelatihan ini, tim pengabdian masyarakat akan memberikan website, fanspage, instagram dan youtube untuk produk sirup markisa yang telah dibuat. Selanjutnya, tim pengabdian masyarakat memberikan pelatihan penggunaan website, fanspage, instagram dan youtube untuk pemasaran produk sirup markisa secara online.

4. Pendampingan penggunaan media pemasaran baik secara langsung dengan datang ke lokasi mitra maupun pendampingan secara tidak langsung dengan berkomunikasi melalui whatsapp atau media komunikasi yang lain.

5. Evaluasi, Setelah kegiatan PKM selesai dilaksanakan, Tim pengabdian masyarakat akan melakukan monitoring dan evaluasi terhadap keberlanjutan usaha mitra dari aspek pemasaran online. Kegiatan monitoring dan evaluasi yang dilaksanakan oleh Tim pengabdian masyarakat meliputi: evaluasi penggunaan website, fanspage, intagram dan youtube dalam memasarkan produk sirup markisa secara online.

\section{HASIL DAN PEMBAHASAN}

Pelatihan digital marketing ini diselenggarakan di tempat mitra PKM. Gambar 1 menunjukkan bahwa pemateri sedang memberi pelatihan dan pendampingan tentang digital marketing (Instagram, fanspage, dan youtube) kepada mitra. Mitra diberikan modul pelatihan digital marketing agar dapat dipelajari selama dan setelah pelatihan (https://drive.google.com/file/d/1s1HC 509UzDy8G0cL0XEKPYzGamFMy8 C8/view?usp=sharing). Selain itu, pemateri juga membuatkan beberapa video tutorial tentang digital marketing yang diupload di youtube, yang meliputi:

1. Video tutorial mendaftarkan akun instagram menggunakan laptop/komputer

(https://www.youtube.com/watch?v $=-\mathrm{aBII} 82 \mathrm{NVM} 0$ )

2. Video tutorial cara mengupload foto dan video di instagram menggunakan perangkat handphone (https://www.youtube.com/watch?v $=0 \mathrm{gs} 0 \mathrm{p} 1$ Rykik)

3. Video tutorial membuat akun fanspage menggunakan $\mathrm{hp}$ (https:/www.youtube.com/watch?v $=$ ych8s95IiAA)

4. Video Tutorial membuat akun fanspage menggunakan laptop/komputer (https://www.youtube.com/watch?v =OWEhFyoP-qQ) 


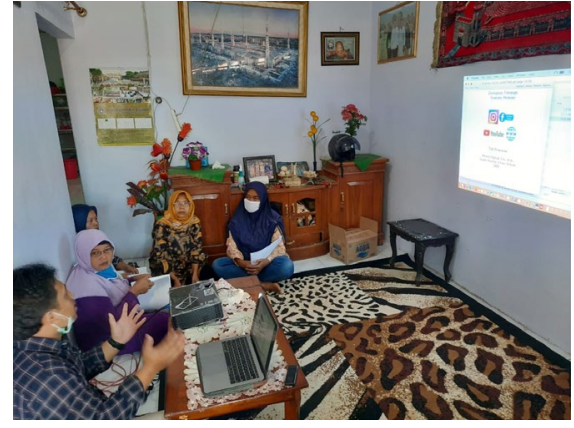

Gambar 1. Tim pengabdian kepada masyarakat sedang memberikan materi pelatihan digital marketing (Instagram, fanspage, dan youtube)

Gambar 2 menunjukkan bahwa pemateri sedang memberi pelatihan tentang pengelolan webiste kepada mitra. Sebelum memulai pelatihan website, pemateri memberikan materi tentang pentingnya website dalam pemasaran produk secara online. Pelatihan dilanjutkan dengan praktik langsung agar para peserta pelatihan lebih mudah memahami dan mempraktikkan materi tentang pengelolaan website.

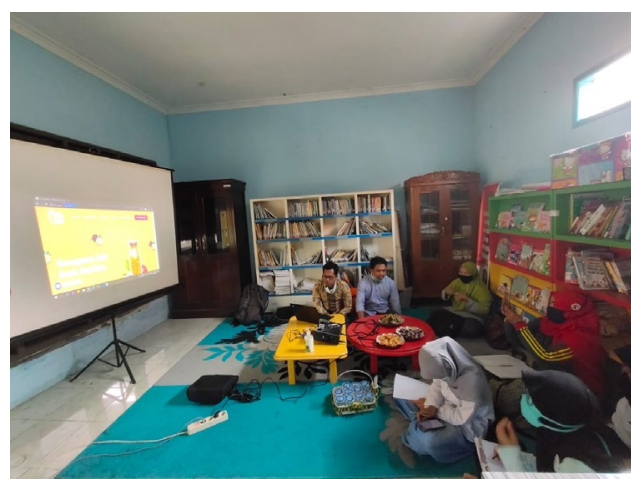

Gambar 2. Tim pengabdian kepada masyarakat sedang memberikan materi pelatihan website

Adapun output dari pelatihan digital marketing ini meliputi: 1. akun Instagram 2. akun fanspage 3. akun youtube dan 4 . website yang diberikan kepada mitra untuk dijadikaan sebagai media pemasaran sirup markisa secara online.

\section{Website untuk penjualan sirup markisa secara online}

Kondisi

sebelum dilaksanakannya PKM, mitra belum mempunyai website untuk penjualan produk markisa. Padahal untuk meningkatkan jangkauan pemasaran sangat dibutuhkan peran digital marketing/online marketing, yang alah satunya adalah website. Dengan adanya website seperti yang ditunjukkan dalam Gambar 3, produk sirup markisa akan lebih banyak dikenal secara nasional maupun internasional sehingga akan meningkatkan jumlah customer yang berujung pada peningkatan omset atau income. Selain itu, peran website untuk produk sirup markisa akan membuat usaha tersebut menjadi lebih professional. Dalam program PKM ini, tim pelaksana membantu membuatkan website untuk mitra dan memberikan pelatihan kepada mitra terkait cara menggunakan dan mengelola website untuk penjualan sirup markisa.

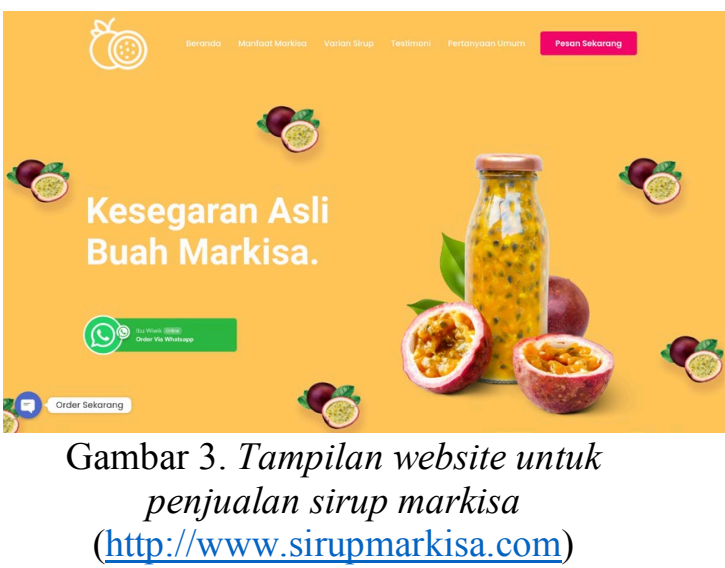

\section{Instagram untuk penjualan sirup markisa secara online}

Sebelum dilaksanakannya PKM, mitra juga belum mempunyai Instagram yang digunakan untuk membantu peningkatan penjualan sirup 
markisa. Di era digital seperti ini, peran Instagram sangat diperlukan untuk membantu pemasaran produk. Dewasa ini, banyak usaha-usaha yang berkembang dengan pemanfaatan Instagram untuk media pemasaraan online. Oleh karena itu, tim pelaksana PKM memberikan pelatihan kepada mitra terkait cara membuat dan mengelola Instagram untuk penjualan produk sirup markisa. Hasil dari pelaatihan Instagram ditunjukkan dalam Gambar 4.

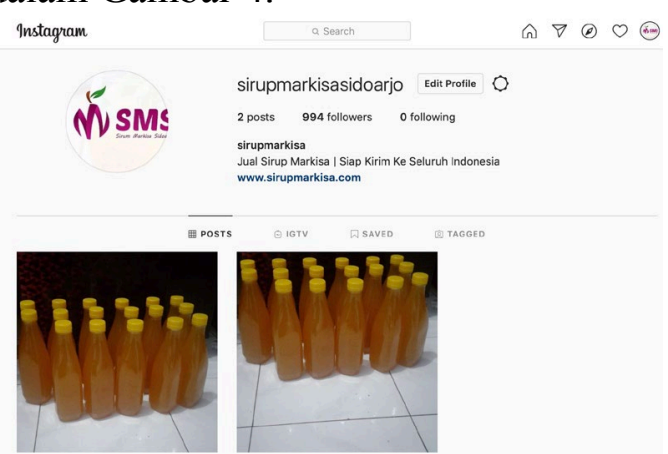

Gambar 4. Tampilan instagram untuk penjualan sirup markisa

https://www.instagram.com/sirupmarkisasi doarjo/

\section{Fanspage untuk penjualan sirup markisa secara online}

Dalam pelaksanaan PKM ini, tim pelaksana juga memberikan pelatihan kepada mitra tentang cara membuat fanspage di facebook. Keuntungan mitra jika mempunyai fanspage adalah mitra dapat memposting foto atau video yang berhubungan dengan produk sirup markisa sehingga dapat menjangkau lebih banyak calon konsumen. Selain itu, artikel yang sudah dipublikasikan di website juga dapat dishare di fanspage sehingga meningkatkan jumlah pengunjung website. Outpur dari pelatihan fanspage ditunjukkan pada Gambar 5.

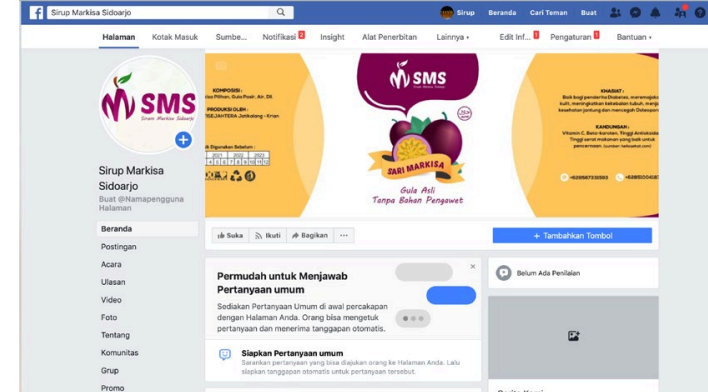

Gambar 5. Tampilan fanspage untuk penjualan sirup markisa

https://www.facebook.com/Sirup-Markisa$\underline{\text { Sidoarjo-100116598476218 }}$

Youtube untuk penjualan sirup markisa secara online

Untuk memaksimalkan pemasaran secara online, tim PKM juga memberikan pelatihan terkait cara membuat akun youtube dan cara memposting video di youtube. Videovideo yang berhubungan dengan produk mitra dapat diupload di youtube, seperti tampak pada Gambar 6. Konten audio dan visual dari produk sirup markisa perlu disebar luaskan secara online melalui youtube. Dengan demikian, akan meningkatkan trust atau kepercayaan calon pembeli.

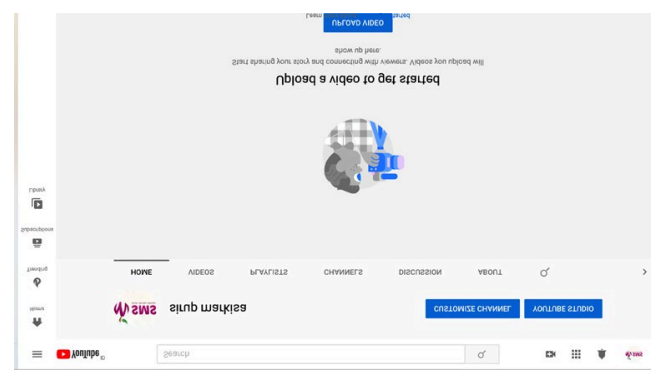

Gambar 6. Tampilan youtube untuk membantuk peningkatan penjualan sirup markisa

https://www.facebook.com/Sirup-Markisa$\underline{\text { Sidoarjo-100116598476218 }}$ 
Kegiatan pelatihan digital marketing ini juga disertai dengan pretest dan post-test sebagai salah saru evaluasi kegiatan pelatihan dengan caraa menyebarkan kuisoner kepada peserta pelatihan. Adapun hasil evaluasi kegiatan pelatihan digital marketing dapat dilihat di Tabel 1 dan 2 .

Tabel 1. Peningkatan pengetahuan mitra

\begin{tabular}{cccc}
\hline \multirow{2}{*}{ No } & \multirow{2}{*}{ Jenis Pelatihan } & \multicolumn{2}{c}{ Pengetahuan Mitra (0-100) } \\
\cline { 2 - 4 } 1 & Pelatihan instagram & Sebelum PKM & Setelah PKM \\
2 & Pelatihan fanspage & 40 & 90 \\
3 & Pelatihan youtube & 40 & 80 \\
4 & Pelatihan website & 20 & 80 \\
\hline
\end{tabular}

Tabel 2. Ketrampilan mitra terkait setelah pelatihan digital marketing

\begin{tabular}{clc}
\hline No & \multicolumn{1}{c}{ Jenis Pelatihan } & Ketrampilan Mitra $(0-100)$ \\
\hline 1 & Pelatihan instagram & 85 \\
2 & Pelatihan fanspage & 85 \\
3 & Pelatihan youtube & 80 \\
4 & Pelatihan website & 70 \\
\hline
\end{tabular}

Berdasarkan Tabel 1, dapat diketahui adanya peningkatan pengetahun mitra tentang Instagram, fanspage, youtube dan website. Peningkatan pengetahuan mitra tertinggi terjadi pada pelatihan insagram. Hal ini dikarenakan sosial media Instagram sudah cukup familiar di masyarakat khususnya mitra PKM. Di sisi lain, tingkat pengetahuan mitra terkait website paling rendah jika dibandingkan dengan yang lain. Hal ini menujukkan bahwa mitra masih belum familiar dengan website. Oleh karena itu, masih diperlukan pendampingan selama program kemitraan masyarakat (PKM).

Tabel 2 memperlihatkan adanya peningkatan ketrampilan mitra dalam mengaplikasikan Instagram, fanspage, youtube, dan website. Sebelum pelatihan digital marketing dimulai, mitra PKM memberikan informasi kepada tim pengabdian masyarakat bahwasanya belum ada pelatihan digitial marketing (Instagram, fanspage, youtube dan website). Akan tetapi, hasil pelatihan digital marketing ini menujukkan hasil yang bagus dilihat dati nilai ketrampilan mitra tentang digital marketing berkisar antara $70-85$.

\section{KESIMPULAN}

Pelatihan digital marketing (instagram, fanspage, youtube dan website) dengan mitra usaha pembuatan sirup markisa dapat terselenggara dengan lancar. Kegiatan pelatihan ini memberikan pengetahuan dan keterampilan kepada mitra tentang cara membuat dan mengelola instagram, fanspage, youtube dan website yang digunakan dalam pemasaran sirup markisa secara online.

\section{UCAPAN TERIMA KASIH}

Tim pengabdian masyarakat mengucapkan terima kasih yang sebesar-besarnya kepada Lembaga Penelitian dan Pengabdian Masyarakat (LPPM) Universitas Maarif Hasyim Latif (UMAHA) Sidoarjo dan 
Direktorat Riset dan Pengabdian Masyarakat Deputi Bidang Penguatan Riset dan Pengembangan Kementerian Riset dan Teknologi/Badan Riset dan Inovasi Nasional yang telah memfasilitasi dan membiayai kegiatan pengabdian kepada masyarakat skema Program Kemitraan Masyarakat (PKM) Tahun Pelaksanaan 2020.

\section{REFERENSI}

Artaya, I. P., \& Purworusmiardi, T. (2019). Efektifitas Marketplace Dalam Meningkatkan Konsentrasi Pemasaran Dan Penjualan Produk Bagi Umkm Di Jawa Timur. Universitas Narotama. Surabaya.

Ermayda, R. Z., Nanda, H. I., \& Narullia, D. (2019). DIGITAL MARKETING SEBAGAI STRATEGI PEMASARAN PRODUK PKK. Jurnal Pengabdian Untuk Mu NegeRI, 3(2).

Harto, D., Pratiwi, S. R., Utomo, M. N., \& Rahmawati, M. (2019). Penerapan Internet Marketing Dalam Meningkatkan Pendapatan Pada UMKM. JPPM (Jurnal Pengabdian Dan Pemberdayaan Masyarakat), 3(1), 39-45.

Khairani, Z., Soviyant, E., \& Aznuriyandi, A. (2018). Efektivitas promosi melalui instagram pada umkm sektor makanan dan minuman di Kota Pekanbaru. Jurnal Benefita: Ekonomi Pembangunan, Manajemen Bisnis \& Akuntansi, 3(2), 239-247.

Ratnadewi, Novie Theresia Br. Pasaribu, Agus Prijono, Aan Darmawan Hangkawidjaja, E. M. S. (2019). Pendampingan Komunitas Women Entrepreneur melalui Literasi Marketing Online di Jawa Barat. Engagement:
Jurnal Pengabdian Kepada Masyarakat, 3(2), 194-207.

Triandini, E., Suradarma, I. B., \& Indrianto, I. (2019). Pemanfaatan Digital Marketing Untuk Meningkatkan Pemasaran Pada Dany Collection. SNPMas: Seminar Nasional Pengabdian Pada Masyarakat, 21-28.

Triono, B. R. M. S., \& Sari, C. T. (2017). Efektivitas Strategi Pemasaran Online bagi Museum Kraton Kasunanan Surakarta. Wasana Nyata, 1(2), 14-20.

Ulfa, M., \& Musadad, M. (2018). Efektifitas Instagram dalam mempromosikan penjualan kamar Batiqa Hotel Pekanbaru. Riau University.

Yudaninggar, K. (2019). PELATIHAN DIGITAL MARKETING DALAM RANGKA PENINGKATAN PEMASARAN KELOMPOK BATIK SOJIWAN. PROSIDING SEMINAR HASIL PENGABDIAN MASYARAKAT, 229-234.

Zulfikar, F., \& Supriyoso, P. (2019). Efektivitas Penjualan Online Melalui Media Sosial Pada Perusahaan $\mathrm{Cv}$ Billionaire Sinergi Korpora (Billionaire Store). Prosiding FRIMA (Festival Riset Ilmiah Manajemen Dan Akuntansi), (2), 909-913. 